\title{
Language for Resilience: Semantic Mapping and Syrian Refugees
}

\author{
hana Al-Badou, dina Al-Jamal, and Imad Sa'di
}

\begin{abstract}
The aim of this study is help refugees to move forward by the means of having control on their English language learning. To this end, semantic mapping was used in teaching reading skills for Eighth grade students at Alzaatari camp for Syrian refugees at the north of Jordan. The researcher used quasi experimental design entailing a pre-post-test and a questionnaire to examine the effect of improving the English reading skills for the participants of the study who were 50. The results of the study showed that semantic mapping strategy improved students' reading skills significantly and thereby improved their resilience by helping themselves to move forward.
\end{abstract}

Keywords: Alzaatari camp, resilience, Syrian refugees, Yarmouk University.

\section{Introduction}

Resilience has many merits relevant to pedagogy in addressing the problems of society. Actually, it aims at helping individuals accommodate life pressure easily. On the issue of language, resilience is used worldwide to responsibilize individual citizens towards local network; it is known as an "object of knowledge in the societal safety and security discourse, resilience is, with a few academic and critical exceptions, seen as positive and desirable regardless of specifics; few argue that the human ability to adapt to dynamic threats and risks is negative" (Bergström, 2018, p. 36). As far as language is concerned, resilience may be useful in helping individuals improve their language; and thereby helping themselves.

Youth of high resilience use more words representing their emotions and time confidently, and here they became closer to positive word vector. Of course, language resilience considers mostly developing the language of youth in order to help them develop themselves (Li et al., 2019). Language is significant in helping refugees to establish social support with the world. The British Council (2018) stated that language is essential for refugees who are displaced from their homes by conflict and civil unrest. Specifically, effective communication enables them to have access to essential services. Of course, education and career opportunities for both children and adults are severely disrupted, or halted. On top of this, language can help refugees to recover from crisis, to withstand challenges and to overcome barriers and bad circumstances.

Nowadays, English language is the first international language used to cope with developments and communication worldwide. Hence, a suitable strategy that facilitates its learning is an urge to help learners practice language skills meaningfully. To learn any language effectively, there is a need for practicing its skills such as words, pronunciation, listening, writing and speaking. Also, there is a need for a suitable strategy or technique to facilitate language teaching processes.

Reading comprehension is considered an essential component for every EFL classroom (Fraihat, 2018; Parker, 2019). Reading develops other language skills (McShane, 2005). To this end, Gutheil and Brodsky (2011) underlined the significance of reading in motivating students to use the language efficiently. Nagy (1988) established three crucial properties of developing reading comprehension skills. These properties are: integration, repetition and meaningfulness. 
In this regard, Mastropieri et al. (2003) used inspiration software to generate spatially organized graphic organizers to facilitate reading comprehension for struggling students.

There are many reading skills that the students can have in order to comprehend a given reading text. For example, Mikulecky (2008) stated that reading skills help students to comprehend given reading texts. She added that fluent readers apply the reading skills consciously and unconsciously. More specifically, she identified the reading skills as" the cognitive processes that a reader uses in making sense of a text"(2008, p. 6). Moreover, she mentioned a number of reading skills such as skimming, scanning, recognizing topics, stating the main idea, recognition pattern of relationships, guessing the meaning of unknown words, paraphrasing, summarizing, drawing references and using evidence, reading critically, reading fast, inferring the main idea, and adjusting reading rate according to materials and purpose (Mikulecky, 2008). Similarly, Afflerbach et al. (2011) confirmed that reading skills are important to conceptualize and teach reading effectively.

The use of combined multiple strategies can be more effective in improving reading comprehension skills. In this concern, Shanahan (2005, p. 33) highlighted some strategies that are successful on reading comprehension which are "summarization, questioning, story map, comprehension monitoring, and graphic organizers". Similarly, Gagen (2007) identified other strategies such as: facilitating the learning process by using cooperative learning, giving overview for the reading text, helping the students to identify the important and main ideas of themes in the text and recognizing the structure of the text, using summarizing, inviting the students to stop at certain sentences or paragraphs on the texts and using graphic organizers.

One strategy that proved its effectiveness in facilitating the learning process is graphic organizers. Graphic organizers are defined by Ciascai (2009, p. 9) as "representations, pictures or models" used for processing visual information. Semantic mapping is one type of graphic organizers (Chang et al., 2006). It is rather described by Krisnawati (2014) as a useful technique to facilitate students' comprehension of the text.

Bleckley (2006) maintained that semantic mapping consists of building relation between new words and pervious words that the learners are already familiar with. Thereby it helps students to expand these words by making relations between the vocabulary items and students' prior knowledge in order to produce meaningful clusters or to even to develop the reading comprehension per-se (Brown, 2001; Nation, 2001; Kustati \& Al-Azmi, 2018). Moreover, Zaid (1995) maintained that teachers can use the stages of reading which are prereading, during-reading and post-reading to use the semantic mapping strategy during the lesson as assignments. This study focuses on reading skills on English language by using the semantic mapping strategy for the refugees. The participants of the study are female eighth grade students who study Action Pack 8. Specifically, these Syrian refugees live in small caravans and their lives still unstable and they suffer hard life circumstances.

According to the teachers at Alzaatari camp, Syrian refugees have noticeable weakness on English language skills. This can be attributed to the difficult circumstances that they and their families had during the war since 2011. Besides, they had hard life circumstances at the camp; as most of the female students get married or engaged at early ages. Sometimes, one can find moms and divorced female students in the eighth grade. Not only this but also, some of them drop out schools for years and they get back again with very poor English language skills. All of these obstacles may demotivate the students to improve their second language. Accordingly, there is a serious need for using strategies to facilitate their learning process. Hence, semantic mapping strategy may have a potential effective effect not only on students' vocabulary and reading skills, but also on their resilience as well. This study aims to answer the following questions: Are there any statistically significant differences at $(\alpha=0.05)$ in the students' reading skills test scores that are attributed to the teaching strategy (namely; semantic mapping vs. the conventional)?; What are the attitudes of the female eighth grade students towards semantic mapping strategy? 


\section{Semantic Mapping and Reading}

Fraihat (2018) highlighted the significance of graphic organizers on improving reading skills. Explicitly, Fraihat stated: "reading comprehension is a significant skill since it is the best indicator of the effectiveness of the interaction between the reader on one hand and a certain type of reading text on the other" $(2018$, p. 1). Also, she added that the teacher can use semantic maps as a pre-assignment strategy as during reading and post reading strategy. This means that, the teacher can use semantic maps to present the lesson on stages or steps on order to help the students understand and follow up themes or ideas that occur on it. Alyousef (2006) confirmed that teachers have the responsibility of choosing appropriate materials and strategies that motivate students to learn reading. Ferris and Hedgcock (2009) referred to these stages as: prereading, while- reading and post reading, and thereby each stage helps learners to understand any given text better.

Interestingly, semantic mapping is considered a useful strategy of learning reading for students who lack prior knowledge and for students who have a prior knowledge of the text. Little and Box (2011) studied the effect of using semantic mapping on learning reading comprehension. The results of their research showed that semantic mapping can significantly affect students who previously lack prior knowledge on new content of reading materials. Also, their research revealed that semantic mapping can help the students to have better understanding of vocabulary and content of the reading texts, too.

Srinivasan et al. (2017) confirmed that semantic mapping is a useful strategy in learning language; especially for children, because they used it to infer word meanings. To this end, the researchers recommended using semantic mapping in teaching vocabulary items to help the learners infer the meaning of the texts. Krisnawati (2014) stated the role of semantic mapping on reading as a facilitator of gathering resources simultaneously; here, students are enabled more to assimilate, understand and evaluate the information to be read.

Anderson (1999) described a reading lesson based on the semantic mapping strategy. At first, the teacher asks the students questions about the topic and the content of the passage. Then, the teacher gives the students a key word. Now, students make a brainstorming in order to generate other words relevant to the key word. Here, a connection between their prior knowledge and the new one is established. After that, the students should understand the structure of the text in order to understand better. The teacher may give feedback on text types. Then, the students are expected to make predictions about what the text will present or about the upcoming content of the text which, in turn, may enable them to make predictions or hypotheses. Finally, the students are invited to connect the ideas and the key words that they are encounter in the text with the ones that they studied before and with what they predict. Interestingly, students can use this strategy and monitor its use outside the classroom activities as well.

\section{Refugees}

Luigi (2015, p. 2) stated that " Since the outbreak of the conflict in Syria, it is estimated that almost 4 million people have fled seeking refuge in neighboring countries: Lebanon, Iraq, Turkey and Jordan". In addition, the researcher noted that according to the UNHCR, the number of Syrian refugees in Jordan as of February 2015, is over 622,000. Refugees in Jordan are suffering of hard life at the camps despite the given aids. Also, the researcher added that the European Union IDs are not adequate. UNHCR stated that "the EU response to the Syrian crisis has been inadequate" (2015, p. 9).

The life of the girls or females at Alzaatari camp is described as full of misery and hard that lacks the essential needs for the healthy and comfortable life for woman. Hattar-Pollara 
(2019) discussed the barriers of education of Syrian refugee girls at Alzaatari camp in Jordan. Hattar-Pollara used qualitative non-experimental design utilizing focus group discussion, interviews for individuals, and observation for participants and nonparticipants of the study. Also, she used the format for focus group discussion, the United States Human Rights module to educate the students and to empower the knowledge and skills. The data were collected by using digital records; observation notes flip chart, detailed interview schedule, demographic tools, narrative statement and content analysis. The findings of her study revealed that the girls at Alzaatari camp face conflicts and daily adverse experiences that affect negatively their psychological and physical health, gender-based abuse along with the early marriage, depression, and suicidal ideation. Also, there are social and economic challenges, anxiety, lifethreatening physical morbidities, and post-traumatic stress.

From the above, the girls at Alzaatari camp have a difficult and tough life, which, in turn, may affect their educational level and achievement. This situation may need to be altered by examining instructional strategies that may help the female students to improve their education with reference to their English language.

El-koumy (1999) examined the effectiveness of three strategies of semantic mapping for teaching English language, and these strategies are: student-meditated semantic mapping, teacher-initiated semantic mapping and teacher-student interactive semantic mapping. The participants of the study were 187 students at the university level, and they were assigned randomly to three groups. Also, the program was administrated over five months for one period for each week. A pre-posttest was used to examine the effectiveness of semantic mapping strategy on the three groups. The pretest showed no significant differences between the three groups, while the posttest showed higher significant differences for the group that used teacherstudent interactive semantic mapping.

Darayseh and Smadi (2003) designed a program based on using semantic mapping and brainstorming. The researchers applied the program to develop 1st scientific secondary students' English writing and reading abilities. The study had control group and experimental group, and the experimental group used the semantic mapping strategy and brainstorming strategies to learn English as a second language; while, the control group used the conventional methods of learning English language. The results of the study showed significant differences between the mean scores of the students of the experimental group and the control group, and these significant differences are attributed to the use of semantic mapping strategy.

Saqqa (2006) studied the effect of using semantic mapping and brainstorming on reading and writing skills in English for tenth grade students. The study consisted of 103 students from the tenth grade who were females. The study reported that, students who studied reading texts by semantic mapping and brainstorming had higher performance levels in comprehension and writing skills than other students who did not use these strategies.

Banisalameh (2010) used semantic mapping on Hashemite University students' to enhance their reading comprehension. The researcher used two strategies for teaching reading which are: semantic mapping and questioning reading. The study consisted of control group which used the conventional method of learning, and the experimental group which used the semantic mapping to enhance the reading strategy. The study reported that students who used the semantic mapping and questioning reading strategies had better performance scores than students who did not use such strategies. Also, the researcher recommended that the semantic mapping and questioning reading are considered effective of teaching and learning the second language and for enhancing the reading comprehension.

Mede (2010) examined the effects of using graphic organizers on student' application of the visual displays in text, and examined the students' attitudes towards the reading skill. The researcher used many instruments of the study which are: pre-post questionnaires, think loud and visual displays. The findings of the study gave a positive attitude towards using graphic organizers, and they improved the students' reading skill. 
Alqatanani (2017) investigated the effects of using thinking maps and multiple intelligences to improve the tenth grade students' critical and creative reading skills. The participants of the study were 877 tenth grade students, and the instruments were: tests for critical and creative reading, and interview. The results of the study showed high significant differences between the experimental and the control groups, and there was positive attitude about the use of the thinking maps strategy.

Elahi and Shangarffam (2017) studied effect of using semantic mapping and mnemonics on EFL learners' vocabulary achievement. The participants of the study were 50 male students in the elementary school from a public language school in Tehran. The researcher chose the participants according to their administrating the Key English Test (KET), and they were selected from among 70 sampled students. After that, the researchers divided the participants onto two experimental groups which are mnemonic group and semantic mapping group. The two groups received 12 sessions of instruction and the pre-post test were conducted to see the results of vocabulary learning. The results of the study showed that there was no significant difference between using mnemonic techniques and semantic mapping strategy on EFL elementary learners' vocabulary achievement.

Hamdan and Alharbi (2017) investigated the use of semantic mapping strategy to teach new vocabulary on reading texts for the EFL Saudi female students at preparatory-year. The participants of the study were 50 students divided onto two groups which are experimental and control groups. The control group was taught by the conventional method and the experimental group was taught by using semantic mapping methods which are: example map, fishbone map concept categories map, compare- contrast map, definition, hierarchical organization map and description. The study followed the quasi-experimental design (pre-posttest) and a questionnaire which was given to the experimental group to evaluate the mentioned types of semantic mapping. The results of the study revealed that semantic mapping strategy had a significant effect on the students' vocabulary and reading performance. Also, there was positive attitude towards using semantic mopping strategy and the highest evaluation was for concept maps, and then a compare- contrast maps. As well as, the researchers recommended to use semantic mapping on teaching vocabulary and reading and to improve the students' attitude towards learning the second language (Kaya, 2015; Raza, 2018).

Fraihat (2018) examined the effect of using graphic organizers with three types of organizers which are: semantic mapping, concept mapping and story mapping. The researcher studied the effect of these organizers on the reading comprehension and on the participants' attitudes towards using them. The participants of the study were Jordanian female tenth grade students. The researcher developed an instructional program based on graphic organizers that enable the participant students to use the maps. The results of the study revealed that there is relation between the students' attitude and improving their reading comprehension.

Sasabone et al. (2018) investigated the effect of semantic mapping strategy on reading comprehension. The researcher used a quasi- experimental design that consisted of control group and experimental group, and the participants were selected purposefully. Also, the data collection was done by utilizing TOEFL reading test, and the data were analyzed using in order to obtain the results. The results of the study revealed that the use of semantic mapping contributed to developing students' reading achievement; as there was a significant difference between the mean score of the experimental group with the semantic mapping, and the control group without semantic mapping.

Junaid (2018) studied the effects of using semantic mapping strategy on reading comprehension performance among university Tun Hussien On Malaysian students. The researcher used pre-posttest as an instrument of the study, and the sample of the students was 40 students from one class and all of them received training on using semantic mapping strategy, and the effect of the strategy is based on the differences in the students' performance 
in the pre-posttest. The result of the study showed that semantic mapping strategy is effective in improving students' reading comprehension. Also, all the participants expressed positive feelings about the semantic mapping strategy and all believed that the technique improved their comprehension.

\section{Method}

A quasi-experimental research design of non-equivalent groups was followed. Two classes have been randomly assigned (control vs. control). Semantic mapping in teaching reading skills was used with students at the experimental group; whereas students at the control group were taught in light of the techniques and procedures introduced by the Teacher's Guide. Both groups were selected from a convenient school at the Alzaatari camp.

This study has one independent variable (i.e. the instructional strategy) that has two levels: semantic mapping contrasted with the conventional strategy. Concerning the dependent variables, two variables were into play: reading skills and the attitudes.

\section{Participants}

They were eighth grade female students at Alzaatari Syrian refuges camp. The number of the participants is forty that was drawn from two classes, 20 students for the control group and 20 for the experimental group. The participants come from the same grade; nevertheless, they have different ages and varied life circumstances, that forced some of them to stop the process of their study or simply to come back.

\section{Semantic Mapping Teaching Strategy}

According to the Jordanian general guidelines and general and specific outcomes for the English language (2006), there are specific outcomes that Eighth grade students expected to have when dealing with reading skills. The general outcomes are: using reading strategies to understand simple authentic informational and literary reading material that demonstrate understanding of simple authentic informational and literary reading material, make connection between prior knowledge and experiences and simple authentic informational and literary reading material. While, the specific outcomes are: to use context (e.g., definitions, comprehension/contrast, and clue words), to guess meanings of new words or phrases, to skim and scan reading material to identify relevant information, to relate new ideas to previous beliefs, values and experiences while reading, and to analyze the content of reading material in order to make inferences.

Therefore, the researcher used the reading subskills mentioned by Ferris and Hedgcock (2009) along with the subskills. These subskills are: recognition of words in context, skimming and scanning, identification of main ideas, information sequence recognition and inferencing. This study lasted for two months; ten weeks, two to three periods in each week. 26 periods were tallied at the first semester of the academic year 2019-2020. Also, the instructional material of the study was Action Pack 8 for both groups.

\section{Teaching the control group: Conventional Method}

The teacher taught reading through the method described in the teacher book. Specifically, students read the text, and then they discussed vocabulary items. After that, students answer the questions on the texts. Then teacher asks students to read the text. 


\section{Teaching the experimental group: Semantic Mapping}

The researchers made a plan for each week elucidating what and how reading passages are taught via the strategy under the study (i.e. semantic mapping) More specifically, the targeted lessons were introduced according to the following:

- The teacher showed the students how to draw the semantic mapping by using one of the maps' shapes, and she chose on her example the shape that consisted of four quarters and the main title at the center, and in each quarter the reading skill or subskill that they focused on during the drawing.

- After that, the teacher asked students to focus on the reading skills and subskills which were: recognition of words in context, identification of main ideas, information sequence recognition and inferencing.

- Then, the students can draw the maps, and the teacher asked each student to read their answers or show to her colleagues the map that she is drawn, and asked them to apply that with each reading text.

- Finally, the teacher gave the students unarranged information from the reading text and asked the students to put the information on the correct sequence. Also, the teacher asked them to write the main ideas and the inferencing some information from the text.

\section{Instruments}

In order to achieve the objectives of the study, reading tests as well as an attitudinal scale were developed to measure students' performance on reading and on reliance growth. The reading skills included: recognition of words in context, identification of main ideas, information sequence recognition. The attitudinal scale was developed to ascertain refugees' attitudes about using semantic mapping strategy in challenging reliance. It consisted of 10 items following the Likert Scale from1 (strongly disagree) to 5 (strongly agree).

The test included two reading passages with four types of questions: Wh-questions, multiple choice questions, fill in question, completion question, inferencing question, and rearranging the information question. The total number of the questions was 10 questions, and the total number of the score was 60 . Table 1 presents the specifications of the test with the percentages, domains, questions number and the outcomes.

To ensure the validity of the instruments, professors at Yarmouk University were invited to look into their content of. Then, the referees' comments were taken into consideration, such as the test needs more than 45 minutes to be answered from the students. Then, an official permission from Yarmouk University for Alzaatari camp was obtained.

After two weeks of the pretest on a sample of 15 students, the researcher piloted a posttest on the same sample students who were chosen from female eighth grade students Alzaatari Camp -outside the participants of the study- to ensure the reliability of the test. Also, Pearson correlational coefficient between the first and the second application was calculated. The result between the two applications was measured as 0.82 which indicates that the test is good to be adopted in the final application of the study. This means that the stability is high and it is able to be used for the research studies purposes. 
Table 1

Specifications of the Test

\begin{tabular}{|c|c|c|c|}
\hline Reading Skills & Outcomes & $\begin{array}{l}\text { Question } \\
\text { s }\end{array}$ & $\begin{array}{c}\text { Percenta } \\
\text { ge }(\%)\end{array}$ \\
\hline $\begin{array}{l}\text { Identifying the main ideas of the } \\
\text { passage. }\end{array}$ & $\begin{array}{l}\text { To distinguish the main idea of } \\
\text { the paragraph. }\end{array}$ & Q: 1 & 3.125 \\
\hline $\begin{array}{l}\text { Skimming and extracting } \\
\text { information from the text. }\end{array}$ & $\begin{array}{l}\text { To skim and extract } \\
\text { information from the text. }\end{array}$ & Q: 2 & 9.375 \\
\hline Scanning the right group of words. & $\begin{array}{l}\text { To scan the right answers of } \\
\text { the group of words. }\end{array}$ & $\mathrm{Q}: 3$ & 9.375 \\
\hline $\begin{array}{l}\text { Check the spelling and dictionary } \\
\text { meaning of the words }\end{array}$ & $\begin{array}{l}\text { To check the spelling and } \\
\text { dictionary meaning of the } \\
\text { words }\end{array}$ & Q: 8 & 12.5 \\
\hline $\begin{array}{l}\text { Inferencing the suitable example, } \\
\text { and the benefits of writing }\end{array}$ & $\begin{array}{l}\text { To inference the suitable } \\
\text { example, and the benefits of } \\
\text { writing }\end{array}$ & $\mathrm{Q}: 4,10$ & 6.25 \\
\hline Find Synonyms & To find Synonyms & Q: 5 & 15.625 \\
\hline Find Antonyms & To find Antonyms & Q: 6 & 15.625 \\
\hline $\begin{array}{l}\text { Connect between the vocabulary of } \\
\text { the passage and apply the semantic } \\
\text { mapping strategy }\end{array}$ & $\begin{array}{l}\text { To make connection between } \\
\text { the vocabulary, and to apply } \\
\text { semantic mapping. }\end{array}$ & Qs: 7 & 15.625 \\
\hline $\begin{array}{l}\text { Ordering the phases of the story } \\
\text { chronology }\end{array}$ & $\begin{array}{l}\text { Order the phases on the } \\
\text { chronological order. }\end{array}$ & Q: 9 & 12.5 \\
\hline Total & 9 & 10 & $100 \%$ \\
\hline
\end{tabular}

\section{Findings and Discussion}

To answer the first research question, means and standard deviations of students' performance in experimental and control groups for the fourth sub-skills of reading skills were extracted. Table 2 illustrates the means and standard deviations of reading sub-skills for the experimental group and control group.

Table 2

Reading Sub-Skills for Experimental and Control Groups

\begin{tabular}{llcccc}
\hline \multirow{2}{*}{ Reading subs-skills } & Group & \multicolumn{2}{c}{ Pre test } & \multicolumn{2}{c}{ Post test } \\
\cline { 3 - 6 } Skimming and scanning & Experimental & 10.24 & .00 & 12.00 & 2.26 \\
Identification of main ideas & Control & 10.80 & 1.72 & 10.72 & 1.83 \\
& Experimental & .12 & .00 & 2.00 & .44 \\
Information sequence recognition & Control & .44 & .91 & .64 & .82 \\
& Experimental & 2.44 & .76 & 3.64 & 1.12 \\
& Control & 2.72 & 1.56 & 2.88 & 1.75 \\
Inference & Experimental & 1.56 & .00 & 4.00 & 1.39 \\
& Control & 1.68 & 1.57 & 1.72 & 1.65 \\
\hline
\end{tabular}


It is clear from Table 2 that there are noticeable differences between the mean scores of experimental group performance and the mean scores of control group performance in favour of the experimental group in the fourth reading skills, according to the teaching strategy (semantic mapping vs. conventional).

To investigate the significance of the two group's performance differences in the fourth reading sub-skills, a one way multivariate analysis of covariance (MANCOVA) was conducted to investigate the effects of teaching strategy in the combined reading sub-skills, after controlling the effect of pre-test scores. In order to evaluate multivariate significance, Hotelling's Trace statistic was used. The results indicated statistical significant effect of teaching strategy on the combined reading sub-skills $(F(4,20)=69.790$, Hotelling's Trace $=$ 6.809 , partial Eta squared $=0.872, p=0.00$ ). The partial eta squared value of 0.872 represented that $87.2 \%$ of the variance in the combined variable (the fourth reading sub-skills together) could be explained by teaching strategy.

In order to investigate on which reading sub-skill students in experimental group and control group significantly differed in their performance, Univariate analysis was conducted to investigate the effects of teaching strategy on student's performance in the fourth reading subskills. As in Table (3).

\section{Table 3}

MANCOVA Results for the Effect of Teaching Strategy on Student's Performance

\begin{tabular}{|c|c|c|c|c|c|c|c|}
\hline Source & Reading sub-skills & SS & $d f$ & MS & $\mathrm{F}$ & Sig. & $\eta 2$ \\
\hline \multirow[t]{4}{*}{ Group } & skimming and scanning & 25.029 & 1 & 25.029 & 25.060 & .000 & .363 \\
\hline & identification of main ideas & 26.878 & 1 & 26.878 & 126.250 & .000 & .742 \\
\hline & $\begin{array}{l}\text { information sequence } \\
\text { recognition }\end{array}$ & 10.099 & 1 & 10.099 & 12.343 & .001 & .219 \\
\hline & Inference & 67.841 & 1 & 67.841 & 169.201 & .000 & .794 \\
\hline \multirow[t]{4}{*}{ Error } & skimming and scanning & 43.945 & 44 & .999 & & & \\
\hline & identification of main ideas & 9.367 & 44 & .213 & & & \\
\hline & $\begin{array}{l}\text { information } \\
\text { recognition }\end{array}$ & 36.003 & 44 & .818 & & & \\
\hline & Inference & 17.642 & 44 & .401 & & & \\
\hline \multirow[t]{4}{*}{ Total } & skimming and scanning & 6544.000 & 50 & & & & \\
\hline & identification of main ideas, & 130.000 & 50 & & & & \\
\hline & $\begin{array}{ll}\text { information } & \text { sequence } \\
\text { recognition } & \end{array}$ & 611.000 & 50 & & & & \\
\hline & Inference & 533.000 & 50 & & & & \\
\hline \multirow{2}{*}{\multicolumn{2}{|c|}{$\begin{array}{l}\text { Correct skimming and scanning } \\
\text { ed Totalidentification of main ideas, }\end{array}$}} & 91.520 & 49 & & & & \\
\hline & & 42.880 & 49 & & & & \\
\hline & $\begin{array}{l}\text { information } \\
\text { recognition }\end{array}$ & 79.620 & 49 & & & & \\
\hline & Inference & 124.020 & 49 & & & & \\
\hline
\end{tabular}

In Table 3, students from different groups differ in their performance in skimming and scanning, identification of main ideas, information sequence recognition, and inferencing in favour of experimental group. As such, semantic mapping strategy enhanced student's performance in the in skimming and scanning, identification of main ideas, information sequence recognition, and inference.

To investigate the effect size of teaching strategy on student's performance in skimming and scanning, identification of main ideas, information sequence recognition, and inference of reading skills, partial eta squared values were extracted and employed. The partial eta squared 
values are, $363, .743, .219$, and .794 for skimming and scanning, identification of main ideas, information sequence recognition, and inference, respectively. This means that teaching strategy explained $36.3 \%, 74.3 \%, 21,9 \%$, and $79.4 \%$ of the variance in skimming and scanning, identification of main ideas, information sequence recognition, and inference, respectively.

Syrian refugees are under growing pressure inside and outside at Alzaatari camp in Jordan. This study showed a profound interest in developing their English language for resilience purposes. Specifically, the second question reads as: "What are the attitudes of the female eighth grade students towards semantic mapping strategy?" To answer this question, means and standard deviations of the questionnaire items were extracted. Table 4 illustrates the means and standard deviations for each statement.

\section{Table 4}

Means and Standard Deviations of the Attitudinal Questionnaire

\begin{tabular}{|c|c|c|c|}
\hline No. & Item & Mean & SD \\
\hline 1 & I find the conventional way of learning reading skills boring. & 3.480 & .509 \\
\hline 2 & I find that semantic mapping strategy helps on building relations among is & 3.600 & .500 \\
\hline 3 & I find that semantic mapping helps on memorizing the facts in the given $t$ & 3.400 & .500 \\
\hline 4 & $\begin{array}{l}\text { I find that semantic mapping helps on finding a vision of my future self } \\
\text { refugee. }\end{array}$ & 3.760 & .435 \\
\hline 5 & $\begin{array}{l}\text { I find that semantic mapping helps on improving my daily activities } \\
\text { relationship building. }\end{array}$ & 3.680 & .476 \\
\hline 6 & I do not feel that semantic mapping improves my reading skills. & 3.920 & .276 \\
\hline 7 & $\begin{array}{l}\text { I find that semantic mapping helps on stress management, and for } \\
\text { building and team well-being. }\end{array}$ & 3.640 & .489 \\
\hline 8 & I find that semantic mapping helps on navigating challenges successfully & 3.640 & .489 \\
\hline 9 & $\begin{array}{l}\text { I think that semantic mapping helps on academic achievement in En } \\
\text { language. }\end{array}$ & 3.360 & .489 \\
\hline 10 & $\begin{array}{l}\text { I think that semantic mapping helps on building resilience and wellt } \\
\text { between refugee colleagues. }\end{array}$ & 3.720 & .458 \\
\hline
\end{tabular}

The mean scores and standard deviations were used to explain the student's attitudes toward semantic mapping strategy. Ranges of agreement with the attributions on the survey was determined by using the following rubric: the interval of 1-1.75 showed very low level, the more than 1.76 to 2.51 interval showed low level, more than 2.52 to 3.25 interval showed high level, the more than 3.26 to 4.00 interval showed high level and the more than 4.21 to 5.00 interval showed very high level of agreement with the statement on the survey. As can be seen in Table 4, the results of the descriptive statistics indicated that student's attitudes towards semantic mapping strategy is indicated by the mean scores ranging from 2.80 to 3.920 on a four point scale. With this in mind, students reported high to very high levels of positive attitudes toward the semantic mapping strategy under the study.

According to UNHCR (2015), refugee families perceive themselves already as deprived to families in non- refugee areas. Only $61 \%$ for primary, $23 \%$ for secondary and $1 \%$ for tertiary students go to school as compared to $91 \%, 84 \%$, and 36 of non-refugees respectively. The present study attempted cultivating resilience by making the reading an accessible skill; and thereby improving the well-being of student learning. Considering the hard life of refugees in camps, semantic mapping strategy made reading classes as fun and pleasant. Eighth grade female refugees participating in the study acquired knowledge about language via semantic mapping. One of Syrian refugee' main challenge is building resilience. Of course, once students succeeded to reach top academic levels, their resilience is best built. Thereby, students regulate their mood and tone for English language learning. In the same vein, Fredrickson's (2013) 
“broadening and building" may add to students' expressive development when instructed by a resilient strategy.

Focusing on refugees, the present study identified a strategy (viz. semantic mapping) for planning language in developing the resilience of Syrian refugees with reference to instructional practices. Given a high demand to develop the reading skill, findings reported significant enhancement of comprehension. The prominence of reading comprehension entails using effective strategies in refugee camps. Of course, refugees perceive themselves a lot with underestimated economic, social and politically conditions. They find themselves unable to take part fully in organizations in host nations. Now, language command is a crucial tool for achieving this covert significance is bilingualism and the positive influence of language.

\section{Conclusions}

Based on the result of the study, the study concluded the following:

1. Using semantic mapping improved the participants' reading skills.

2. The participants had high positive attitudes towards using semantic mapping.

3. There is a relationship between the students' reading skills and their attitudes. To this end, language is a tool for improving refugees' resilience.

4. The use of semantic mapping strategy encouraged the students to become strategic readers.

5. Graphic organizers can motivate the students to learn the second language especially reading skills.

The border implications of the study are: Using semantic mapping strategy in teaching the second language and especially reading comprehension skill; Teachers and learners can have benefit from this study by applying semantic mapping strategy in teaching the students at the camps all around the world. This study can be a model that can be imitated by other researchers, teachers, and students in the education and learning fields.

\section{Acknowledgment}

The authors are very thankful to all Syrian refugees, along with the Jordanian teachers in any reference, who contributed in/for the purpose of this research.

\section{Disclosure}

The authors report no conflicts of interest in this work.

\section{Funding Details}

This work was not supported by funding agency.

\section{References}

Afflerbach, P., Pearson, P., \& Paris, S. (2008). Clarifying differences between reading skills and reading strategies. The Reading Teacher, 61(5), 364-373. http://doi.org/10.1598/rt.61.5.1

Alqatanani, A. (2017). The effect of a program based on thinking maps and multiple intelligences on improving the Jordanian tenth grade students' critical and creative reading skills in English (Unpublished doctoral dissertation), Yarmouk University. 
Alyousef, H. (2006). Teaching reading comprehension to ESL/EFL learners. Journal of Language and Learning, 5(1), 63-73.

Anderson, N. (1999). Exploring second language reading: Issues and strategies. Heinle \& Heinle.

Arslan, C., \& Tanis, B. M. (2018). Building English Vocabulary Schema Retention Using Review Value Calculation for ESL Students. Research in Social Sciences and Technology, 3(3), 116-134. https://doi.org/10.46303/ressat.03.03.7

Banisalameh, L. (2010). Designing an English instructional program based on semantic mapping and questioning reading strategies and measuring its effect on Hashemite University students' reading comprehension (Unpublished doctoral dissertation), Yarmouk University.

Bergström, Johan. (2018). An archaeology of societal resilience. Safety Science, 110, 32-38. https://doi.org/10.1016/j.ssci.2017.09.013.

Bleckley, B. (2006). Rethinking vocabulary instruction. Pedagogy in Practice. http://pedagogypractice.blogspot.com/2019/6/6/rethinking

British Council. (2018). Language for resilience. https://www.britishcouncil.org/language-forresilience

Brown, H. (2001). Teaching by principles: An interactive approach to language pedagogy. Person Education.

Chang, W., Juang, Y., \& Huang, K. (2006). Robust integration for speech features. Signal Processing, 86(9), 2282-2288. https://doi.org/1016/j.sigpro.2005.10.020

Ciascai, L. (2009). Using graphic organizers in instructional education. Acta Didactica Napocensia, 2(1), 9-18.

Darayseh, A., \& Smadi, O. (2003). The effect of a proposed program based on semantic mapping and brainstorming strategies on developing the English writing ability and attitudes of the first scientific secondary students (Unpublished doctoral dissertation). Amman Arab University for Graduate Studies.

El-koumy, A. (1999). Effects of three semantic mapping strategies on EFL students' reading comprehension. Education Resources Information Center (ERIC), https://doi.org/10.2139/ ssrn.2365006

Elahi, E., \& Shangarffam, N. (2017). The comparative effect of using semantic mapping and mnemonics on EFL Learners' vocabulary achievement. Journal for the Study of English Linguistics, 5(1), 42-55. https://doi.org/10.5296/jsel.v5i1.10848

Ferris, D., \& Hedgcock, J. (2009). Teaching readers of English students, texts, and contexts. Routledge.

Fraihat, B. (2018). The effect of using graphic organizers on Jordanian female EFL tenth grade students' reading comprehension and their attitudes towards using them (Unpublished Doctoral Dissertation). Yarmouk University.

Fredrickson, B. (2013). Positive emotions broaden and build. In P. Devine, \& A. Plant, (Eds.), Advances in experimental social psychology (Vol. 47) (pp. 301-318). Academic Press.

Gagen, M. (2007). Developing and improving reading comprehension skills: Overview of reading comprehension and specific actions to help students develop comprehension. Retrieved May 1, 2019, from http://righttrackreading.com/readingcomprehension.html

Gutheil, T., \& Brodsky, A. (2011). Preventing boundary violations in clinical practice. Guilford Press.

Hamdan, M., \& Alharbi, N. (2017). The effectiveness of semantic mapping strategy on vocabulary achievement of EFL Saudi female preparatory-year students. Journal of Applied Linguistics and Language Research, 4(7), 14-46. http://www.jallr.com/index.php/JALLR/article/view/667 
Hattar-Pollara, M. (2019). Barriers to education of Syrian refugee girls in Jordan: Gender based threats and challenges. Journal of Nursing Scholarship, 51(3), 241-251. http://doi.org/10.1111/jun.12480

Junaid, T. (2018). The effects of using semantic mapping strategy on reading comprehension performance among UTHM students. International Journal of Engineering \&Technology, 7(3.21), 48-51. https://doi.org/10.14419/ijet.v7i3.21.17094

Kaya, Y. (2015). The Opinions of Primary School, Turkish Language and Social Science Teachers regarding Education in the Mother Tongue (Kurdish). Journal of Ethnic and Cultural Studies, 2(2), 33-46.

Krisnawati, N. (2014). Using semantic mapping to improve $7^{\text {th }}$ grade students' reading comprehension in SMPN 1 Jetis in the academic year of 2013/2014 (Masters' thesis) Yogyakarta State University.

Kustati, M., \& Al-Azmi, H. (2018). Pre-Service Teachers' Attitude on ELT Research. Research in Social Sciences and Technology, 3(2), 1-13. https://doi.org/10.46303/ressat.03.02.1

Li, S., Lu, S., Ni, S., \& Peng, K. (2019). Identifying psychological resilience in Chinese migrant youth through multidisciplinary language pattern decoding. Children \& Youth Services View, 107. https://doi.org/10.1016/j.childyouth.2019.104506

Little, D., \& Box, J. (2011). The use of a specific schema theory strategy - semantic mappingto facilitate vocabulary development and comprehension for at-risk readers. Reading Improvement, 48(1), 24-31.

Luigi, A. (2015). Syrian refugees in Jordan: A reality check. Migration Policy Center, EUI. https://doi.org/10.2870/821248

Mastropieri, M., Scruggs, T., \& Graetz, J. (2003). Reading comprehension instruction for secondary students: Challenges for struggling students and teachers. Learning Disability Quarterly, 26(2), 103-116. https://doi.org/10.2307/1593593

McShane, M. (2005). A theory of ellipsis. London, UK: Oxford University Press.

Mede, E. (2010). The effect instruction of graphic organizers as a reading strategy: Research finding and issues. Creative Education, 3(3), 348-356.

Mikulecky, B. (2008). Teaching reading in a second language. Pearson Education, Inc.

Nagy, W. (1988). Teaching vocabulary to improve reading comprehension. National Council of Teachers of English. https://eric.ed.gov/?id=ED298471

Nation, P. (2001). Learning vocabulary in another language. Cambridge University Press.

Parker, J. (2019). Second language learning and cultural identity. Journal Of Curriculum Studies Research, 1(1), 33-42. https://doi.org/10.46303/jcsr.01.01.3

Raza, K. (2018). Adapting Teaching Strategies to Arab Student Needs in an EFL Classroom. Journal of Ethnic and Cultural Studies, 5(1), 16-26.

Saqqa, S. (2006). The effect of computer assisted semantic mapping and brainstorming on Jordanian upper basic stage students' reading comprehension and writing in English (Unpublished doctoral dissertation). Amman Arab University for Graduate Studies.

Sasabone, L., Yassi, A., \& Imran, N. (2018). Applying semantic mapping to improve students' reading comprehension. Scope of English Language Teaching, Literature and Linguistics, 1(1), 10-16.

Shanahan, T. (2005). The national reading panel report: Practical advice for teachers. Learning Point Associates. https://eric.ed.gov/?id=ED489535

Srinivasan, M., Al-Mughairy, S., Foushee, R., \& Barner, D. (2017). Learning language from within: Children use semantic generalizations to infer word meanings. Cognition, 159, 11-14. https://doi.org/10.1016/j.cognition.2016.10.019

UNHCR. (2015). Left behind refugee education in crisis. Paris: UNESCO Institute for Statistics. 
Al-Badou, $\mathrm{H}$.

Woofter, S. (2019). Book Review: Building Equity: Policies and Practices to Empower All Learners. American Journal of Qualitative Research, 3(1), 136139. https://doi.org/10.29333/ajqr/5815

Zaid, M. (1995). Semantic mapping in communicative language teaching. FORUM, 33(3), 616. 